\title{
Vanadyl Sulfate Treatment Stimulates Proliferation and Regeneration of Beta Cells in Pancreatic Islets
}

\author{
Samira Missaoui, ${ }^{1}$ Khémais Ben Rhouma, ${ }^{1}$ Mohamed-Tahar Yacoubi, ${ }^{2}$ \\ Mohsen Sakly, ${ }^{1}$ and Olfa Tebourbi ${ }^{1}$ \\ ${ }^{1}$ Laboratory of Integrated Physiology, Faculty of Sciences of Bizerte, University of Carthage, 7021 Jarzouna, Tunisia \\ ${ }^{2}$ Department of Pathological Anatomy, Farhat Hached University Hospital, 4000 Sousse, Tunisia
}

Correspondence should be addressed to Mohsen Sakly; mohsensakly@gmail.com

Received 23 May 2014; Revised 7 July 2014; Accepted 28 July 2014; Published 19 August 2014

Academic Editor: Giuseppe Paolisso

Copyright (C) 2014 Samira Missaoui et al. This is an open access article distributed under the Creative Commons Attribution License, which permits unrestricted use, distribution, and reproduction in any medium, provided the original work is properly cited.

\begin{abstract}
We examined the effects of vanadium sulfate $\left(\mathrm{VOSO}_{4}\right)$ treatment at 5 and $10 \mathrm{mg} / \mathrm{kg}$ for 30 days on endocrine pancreas activity and histology in nondiabetic and STZ-induced diabetic rats. In diabetic group, blood glucose levels significantly increased while insulinemia level markedly decreased. At the end of treatment, $\mathrm{VOSO}_{4}$ at a dose of $10 \mathrm{mg} / \mathrm{Kg}$ normalized blood glucose level in diabetic group, restored insulinemia, and significantly improved insulin sensitivity. $\mathrm{VOSO}_{4}$ also increased in a dose-dependent manner the number of insulin immunopositive beta cells in pancreatic islets of nondiabetic rats. Furthermore, in the STZ-diabetic group, the decrease in the number of insulin immunopositive beta cells was corrected to reach the control level mainly with the higher dose of vanadium. Therefore, $\mathrm{VOSO}_{4}$ treatment normalized plasma glucose and insulin levels and improved insulin sensitivity in STZ-experimental diabetes and induced beta cells proliferation and/or regeneration in normal or diabetic rats.
\end{abstract}

\section{Introduction}

Vanadium is a transition metal. It is estimated that more than 60 thousand tons of this element is emitted into the atmosphere each year as the result of human activities mostly from the combustion of fossil fuels [1].

After entering the circulatory system via gastrointestinal or respiratory tract, vanadium compounds are transported by transferrin or, less commonly, by albumin or low molecular components of plasma, such as citrates and, to a lesser extent, lactates or phosphates [2]. Many studies were conducted on inorganic and organic vanadium derivatives in induced diabetes animal models, in which the studied compounds were found to impact the levels of glucose, cholesterol, and triglycerides, with no significant harmful side effects upon prolonged administration [3-7]. Many experiments were also performed in diabetic patients, confirming the therapeutic effect of vanadium compounds on blood glucose levels with little toxic effects [8].
Vanadium (including vanadyl and vanadate) has been shown to reduce blood glucose level by stimulating glycogenesis, glucose uptake, and metabolism and by inhibiting glucose formation via hepatic gluconeogenesis and glycogenolysis $[9,10]$. It has been found that vanadium and vanadium compounds exhibit an insulin-like activity [9, 11-13] by imitating insulin actions via insulin-receptor tyrosine kinase activation and kinase phosphorylation cascade pathways [1417]. Therefore, vanadyl sulfate has been suggested as a therapeutic agent for the treatment of type 1 diabetes [12, 18-20]. Streptozotocin (STZ) treatment destroys the beta insulinproducing cells of the pancreas and STZ-induced diabetic rats are considered as a model of type 1 diabetes mellitus $[21,22]$. Although vanadium compounds have been shown to have antidiabetic properties in STZ-induced diabetic model, the mechanism of their actions remained currently under investigation. The aim of this study was to investigate the responses of 30 days of treatment with vanadium sulfate in nondiabetic and STZ-induced diabetic rats. 


\section{Materials and Methods}

2.1. Preparation of Diabetic Rats. The animals were made diabetic by an intraperitoneal injection (ip) of STZ in a single dose of $65 \mathrm{mg} / \mathrm{Kg}$ in $0.01 \mathrm{M}$ citrate buffer ( $\mathrm{pH} 4.5$ ). This ip method was chosen based on recent reports which demonstrated a pronounced glucose increasing effect in STZdiabetic rats $[23,24]$.

2.2. Animals and Treatment. Male Wistar rats, 5-6-weekold (weighting 175-200 g), were purchased from Pasteur Institute of Tunisia and used in accordance with the Local Ethic Committee of Tunis University for the use and care of animals in accordance with NIH recommendations. They were provided with food (standard pellet diet-Badr Utique$\mathrm{TN}$ ) and water ad libitum and housed five per cage under collected temperature $\left(22^{\circ} \mathrm{C}\right)$ with a 12-hour light-dark cycle. The rats were divided into six groups.

Group 1 was nondiabetic control animals (ND control) and received daily an intraperitoneal injection (ip) of $\mathrm{NaCl}$ $9 \%$. Groups 2 and 3 were ND and received daily a dose of either 5 or $10 \mathrm{mg}$ of $\mathrm{VOSO}_{4} / \mathrm{Kg}$, respectively $(\mathrm{ND}+5 \mathrm{mg} / \mathrm{Kg}$ and $\mathrm{ND}+10 \mathrm{mg} / \mathrm{Kg}$ ), for 30 days. Group 4 was a diabetic control ( $\mathrm{D}$ control) injected with a single dose of $65 \mathrm{mg} / \mathrm{Kg}$ of STZ. Groups 5 and 6 comprised STZ diabetic animals treated with either 5 or $10 \mathrm{mg} / \mathrm{Kg}$ of $\mathrm{VOSO}_{4}$ during 30 days, respectively ( $\mathrm{D}+5 \mathrm{mg} / \mathrm{Kg}, \mathrm{D}+10 \mathrm{mg} / \mathrm{Kg})$. STZ-groups were treated with $\mathrm{VOSO}_{4}$ after 48 hours of STZ-induced diabetes.

2.3. Biochemical Assays. All animals were fasted 12 hours before determination of glycemia by a glucometer (ACCUCHEK-Active Roche). Insulin sensitivity was measured after ip injection of $1 \mathrm{U} / \mathrm{Kg}$ of insulin and blood glucose levels were determined at 30 min intervals during 2 hours as the percent of the hormone level at $t_{0}$.

Animals were sacrificed after 24 hours of the last treatment and the blood was collected and serum was processed for estimation of insulin which was determined by Elisa kit (distributed by BioVendor).

2.4. Immunohistochemical Evaluation. Immunohistochemical staining of insulin was performed in order to characterize the integrity of beta cells in Langerhans islets. For this, tissue sections showing the maximum larger surface of Langerhans islets were selected for comparisons between groups. Sections were firstly deparaffined, hydrated through a decreasing gradual ethanol series, immersed in tampon citrate $(\mathrm{pH} \mathrm{6})$ for $40 \mathrm{~min}$, and then incubated with a polyclonal Guinea Pig anti-insulin antibody diluted in $50 \mathrm{mM}$ Tris- $\mathrm{HCl}, \mathrm{pH}$ 7,6 (DAKO). After washing, sections were incubated with phosphatase conjugated anti-Guinea Pig antibody and the procedure of revelation was assisted by TechMate 500 machine. Finally, sections were stained with haematoxylin/eosin.

Ten pancreatic islets per rat were examined under the microscope and the number of insulin-positive and insulinnegative cells was counted by numbering their nuclei. Data are expressed as the percent of insulin immunopositive cells/total number of cells in each islet.
2.5. Statistical Analysis. Significance of difference among various groups was evaluated by one-way analysis of variance (ANOVA) followed by Tukey's Multiple Comparison test, and $P$ value was taken as significant at 5\% level.

\section{Results}

The effect of $\mathrm{VOSO}_{4}$ treatment on the blood glucose levels in nondiabetic (ND) and diabetic (D) rats is shown in Figure 1. There were no significant changes in the blood glucose levels in control ND group during the treatment (Figure 1(a)). Treatment of ND rats with $\mathrm{VOSO}_{4}$ at 5 or $10 \mathrm{mg} / \mathrm{Kg}$ did not change significantly the blood glucose levels during the first 10 days. However, blood glucose level decreased significantly at the end of treatment with the dose of $5 \mathrm{mg} / \mathrm{Kg}$ and was significantly reduced from 15 to 30 days with the dose of $10 \mathrm{mg} / \mathrm{Kg}$ as compared to control ND group. At day 30, the glycemia decrease was about 8 and 15\%, respectively, for the doses of 5 and $10 \mathrm{mg} / \mathrm{Kg}$ compared to control group. As suspected, a notable increase of blood glucose level was observed in the STZ-treated control rats compared to untreated animals ( $406.25 \pm 16.70$ versus $99.83 \pm 5.19 \mathrm{mg} / \mathrm{dL})$ indicating diabetes installation that was maintained during all experiment. Treatment of diabetic group (D) with $5 \mathrm{mg} / \mathrm{Kg}$ of $\mathrm{VOSO}_{4}$ reduced significantly blood glucose level from day 10 while a dose of $10 \mathrm{mg} / \mathrm{Kg}$ decreased blood glucose level significantly and gradually from day 5 to reach normal level at day 30 . The noted values of glycemia at 30 days were $349.40 \pm$ 16.83 and $138.50 \pm 6.19$ versus $406.25 \pm 16.70 \mathrm{mg} / \mathrm{dL}$, respectively, in D + 5, D + 10, and control D groups (Figure $1(\mathrm{~b})$ ).

Table 1 showed the levels of insulin in ND and D groups without and following $\mathrm{VOSO}_{4}$ treatment. The ND rats treated with $5 \mathrm{mg} / \mathrm{Kg}$ of $\mathrm{VOSO}_{4}$ did not show significant changes in insulinemia level, but a marked increase was obtained with $10 \mathrm{mg} / \mathrm{Kg}$ compared to control ND group $(2.76 \pm 0.07$ versus $1.73 \pm 0.04 \mu \mathrm{g} / \mathrm{L})$. Moreover, in control D group, insulinemia was profoundly decreased in comparison to control ND animals $(0.07 \pm 0.01$ versus $1.73 \pm 0.04 \mu \mathrm{g} / \mathrm{L})$. Administration of $\mathrm{VOSO}_{4}$ in $\mathrm{D}$ groups markedly increased the insulinemia in a dose-dependent manner. In fact, insulin levels were increased in diabetic rats from $0.07 \pm 0.01$ to $0.49 \pm 0.004$ and $1.26 \pm 0.12 \mu \mathrm{g} / \mathrm{L}$ with, respectively, $5 \mathrm{mg}$ and $10 \mathrm{mg} / \mathrm{Kg}$ doses.

Insulin sensitivities changes following the ip injection of insulin $(1 \mathrm{U} / \mathrm{Kg})$ in normal and diabetic treated animals are shown in Figure 2. In ND rats, treatment with 10 or $5 \mathrm{mg}$ of $\mathrm{VOSO}_{4}$ did not alter the glycemia profile in response to insulin administration (Figure 2(a)). Indeed, in these groups, the maximum hypoglycemic effect of insulin was observed by 60 and $90 \mathrm{~min}$, respectively, and was about $40 \%$ of initial glycemia value. Diabetic animals treated with the low dose of $\mathrm{VOSO}_{4}$ showed a similar glycemia profile than control $\mathrm{D}$ group with a maximum decrease by $60 \mathrm{~min}$ while those treated with the high dose exhibited a significant (50\%) and rapid maximum decrease of glycemia by $30 \mathrm{~min}$ after insulin injection (Figure 2(b)).

In $\mathrm{VOSO}_{4}$ treatment groups, the size of pancreatic islets was observed to be larger compared to their respective control ND and D groups (Figures 3 and 4). Statistical analyses 


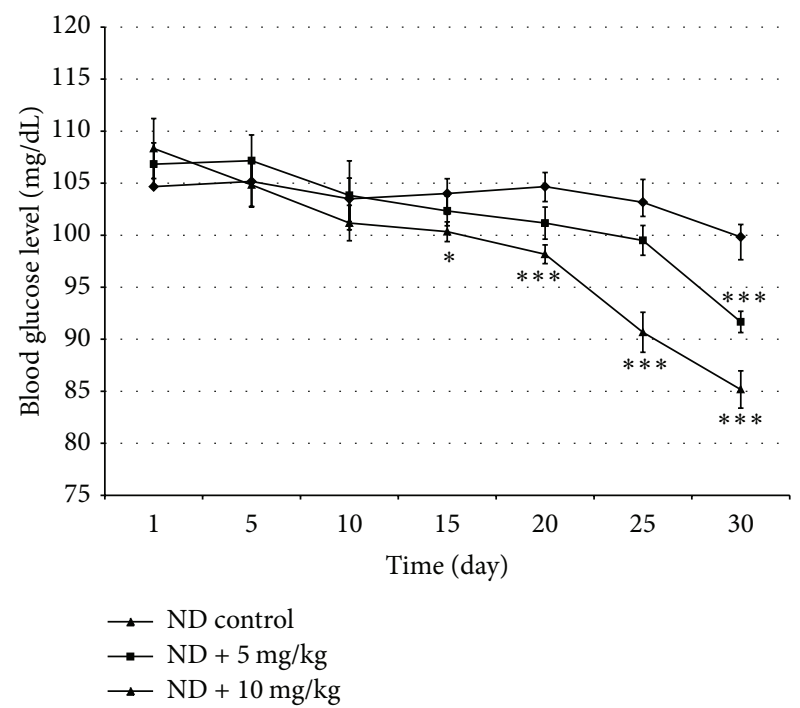

(a)

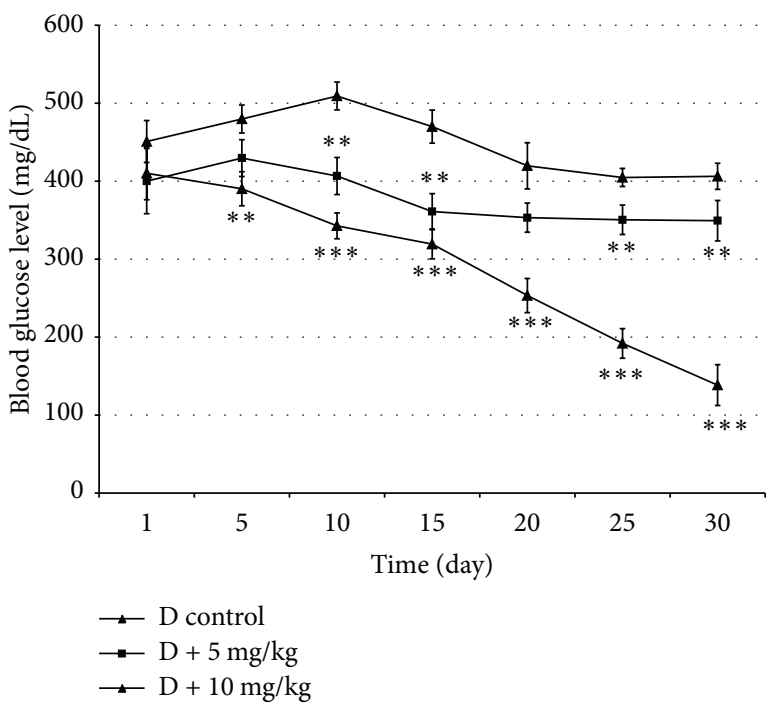

(b)

FIGURE 1: Effects of vanadyl sulfate on blood glucose level in normal (a) and STZ-diabetic (b) rats. Values are mean \pm SD. ${ }^{*} P<0.05 ;{ }^{* * *} P<$ 0.001 versus corresponding control. $N=10$ per group.

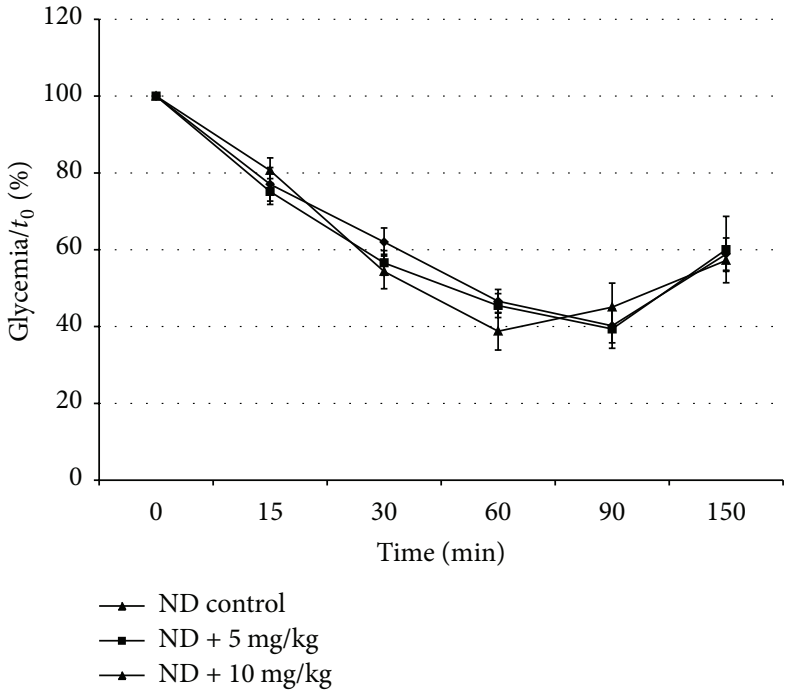

(a)

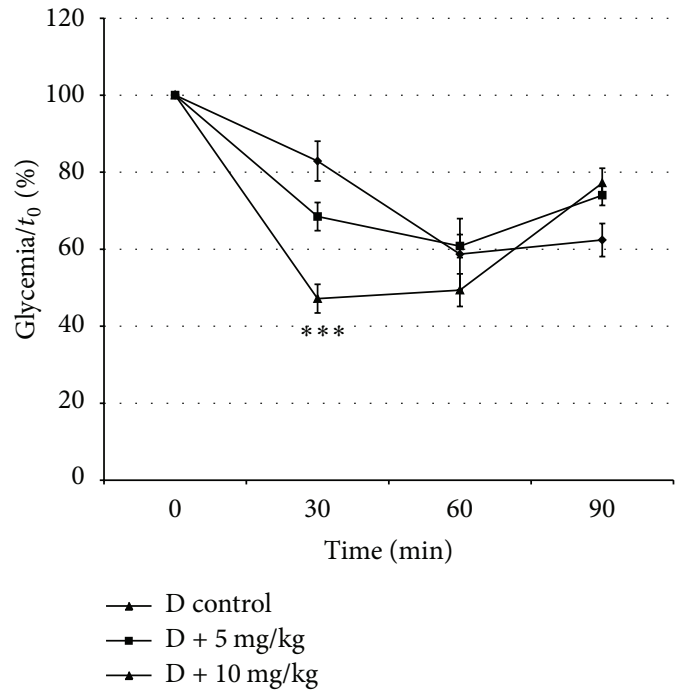

(b)

FIGURE 2: Effect of vanadyl sulfate on the insulin sensitivity in normal (a) and STZ-diabetic (b) rats. Values represent the percentage change from glycemia at $t_{0}$. Values are $\pm \mathrm{SD} .{ }^{* *} P<0.01 ;{ }^{* * *} P<0.001$ versus corresponding control. $N=10$ per group.

TABLE 1: Effects of vanadyl sulfate on insulinemia in nondiabetic and diabetic rats. Values are mean of blood insulin levels \pm SD (standard deviation).

\begin{tabular}{lcccccc}
\hline Group & \multicolumn{3}{c}{ Nondiabetic } & \multicolumn{2}{c}{ Diabetic } \\
\hline VOSO4 mg/Kg & 0 & 5 & 10 & 0 & 5 & 10 \\
Insulinemia $(\mu \mathrm{g} / \mathrm{L})$ & $1.73 \pm 0.04$ & $1.97 \pm 0.12^{\delta \delta \delta}$ & $2.76 \pm 0.07^{* * * \delta \delta \delta}$ & $0.07 \pm 0.01^{* * *}$ & $0.49 \pm 0.04^{* * * \delta}$ & $1.26 \pm 0.12^{* * \delta \delta \delta \pi \pi \pi}$ \\
$n$ & 8 & 6 & 6 & 8 & 7 & 6 \\
\hline
\end{tabular}

$n$ : number of determination used in this experiment.

${ }^{* *} P<0.01 ;{ }^{* * *} P<0.001$ versus ND control.

${ }^{\delta} P<0.05 ;{ }^{\delta \delta \delta} P<0.001$ versus $D$ control.

${ }^{\pi \pi \pi} P<0.001$ versus $\mathrm{D}+5$. 


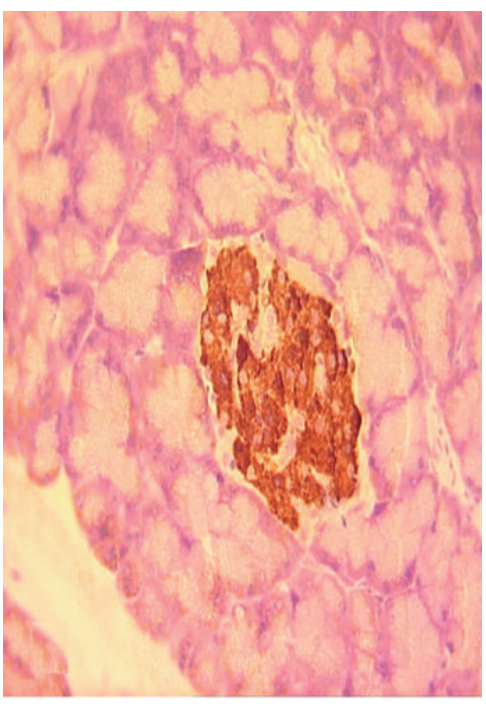

(a)

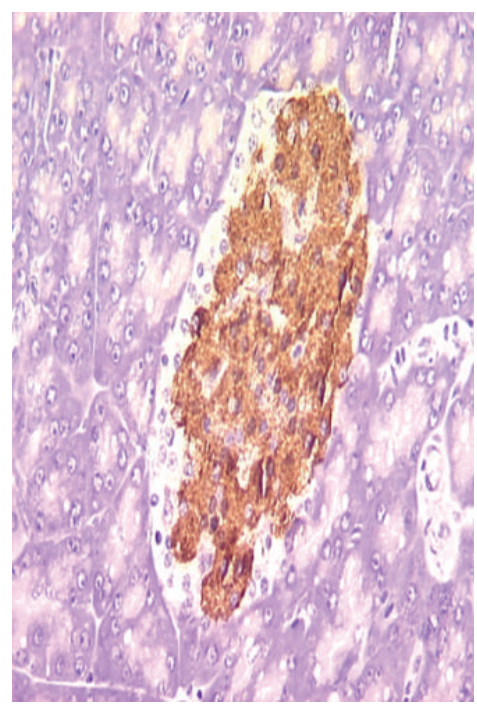

(b)

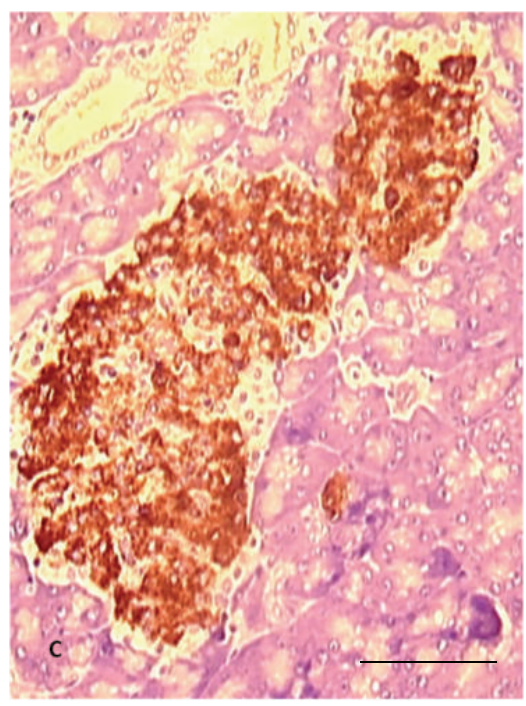

(c)

Figure 3: Immunohistochemical staining of insulin in pancreatic Langerhans islet beta cells from nondiabetic rats. Note that insulin immunopositive cells are greater in (b) and more in (c). Control ND (a), ND treated with $5 \mathrm{mg} / \mathrm{Kg}$ of $\mathrm{VOSO}_{4}$ (b), and ND treated with $10 \mathrm{mg} / \mathrm{Kg}$ of $\mathrm{VOSO}_{4}$ (c). Six rats were used per group and 10 islets per rat were analyzed. Scale bar: $50 \mu \mathrm{m}$.

showed that $\mathrm{VOSO}_{4}$ treatments induced a marked increase in the number of insulin immunopositive cells by about $20 \%$ in $\mathrm{ND}+5$ and $27 \%$ in $\mathrm{ND}+10 \mathrm{mg} / \mathrm{Kg}$ groups (Figure 5). $\mathrm{VOSO}_{4}$ treatment increased significantly the number of insulin immunopositive cells in the STZ-diabetic groups in a dose-dependent manner by 12 and 23\%, respectively, with 5 and $10 \mathrm{mg} / \mathrm{Kg}$ doses (Figure 5). Comparison between STZdiabetic treated groups and ND control rats indicated no significant differences.

\section{Discussion}

We studied the antidiabetic properties of vanadium by exploring its effects on blood glucose and insulin levels as well as $\mathrm{B}$ cells of endocrine pancreas.

Using STZ-induced diabetic rats, we showed that treatment with vanadyl sulfate $\left(\mathrm{VOSO}_{4}\right)$ at 5 and $10 \mathrm{mg} / \mathrm{Kg}$ significantly reduced the mean blood glucose levels by the 10th and 5 th days, respectively, in comparison with untreated control group. At day 30, diabetic rats given the higher dose of the compound exhibited similar glycemia level than ND control animals. However, in ND rats, treatment with the lower dose of $\mathrm{VOSO}_{4}$ did not change significantly the blood glucose level while the higher dose induced little and gradually decrease by the day 15 of treatment and the glycemia was decreased by about $14 \%$ at day 30 . Our results are in agreement with previous data demonstrating that oral administration of vanadium compounds in STZ-induced or genetically inherited or nutritional diabetic animals significantly ameliorated hyperglycemia [25-29]. In humans, Soveid et al. [30] reported the safety and the efficacy of oral vanadyl sulfate therapy during 30-month period in type 1 diabetic patients by decreasing insulin need and blood glucose level.
Our study also revealed that the hypoglycemic effect of $\mathrm{VOSO}_{4}$ was accompanied by a marked increase of basal insulinemia level in diabetic group in a dose-dependent manner. With the dose of $10 \mathrm{mg}$, the insulinemia level of diabetic rats was almost normalized. Indeed, the decrease of blood glucose levels registered particularly in diabetic rats exposed to vanadium compound may be related to the concomitant increase of plasma insulin concentrations. These results were in accordance with previous data concerning the effectiveness of vanadium compounds in ameliorating diabetic state [30-32].

Further, we have investigated the effect of vanadium administration on insulin sensitivity in diabetic and nondiabetic rats. In ND groups, we showed a maximum hypoglycemic effect of insulin at 60-90 min after hormone introduction. However, in $\mathrm{D}$ groups, $\mathrm{VOSO}_{4}$ treatment with a dose of $10 \mathrm{mg}$ enhanced insulin sensitivity with a more rapid and pronounced decrease of blood glucose following hormone injection while the dose of $5 \mathrm{mg}$ did not change significantly the glycemia response of $\mathrm{D}$ rats. The improved insulin sensitivity induced by $\mathrm{VOSO}_{4}$ is in line with numerous studies indicating that vanadium can be considered as a potent insulin mimetic or insulin trophic in various tissues [24, 33].

It has been shown that vanadium compounds are characterized by multiple ways of action resulting in blood sugar decrease [34]. In vivo and in vitro studies reported that vanadyl sulfate increased glucose transport and metabolism in skeletal muscles, liver, and adipose tissues [25]. Thanks to their structural similarity to orthophosphate anions, the vanadium organic derivatives inhibit protein phosphotyrosine phosphatase [35]. They also inhibit the activity of PTP-1B, enzyme responsible for the dephosphorylation of insulin receptor, causing insulin resistance $[36,37]$. Another 


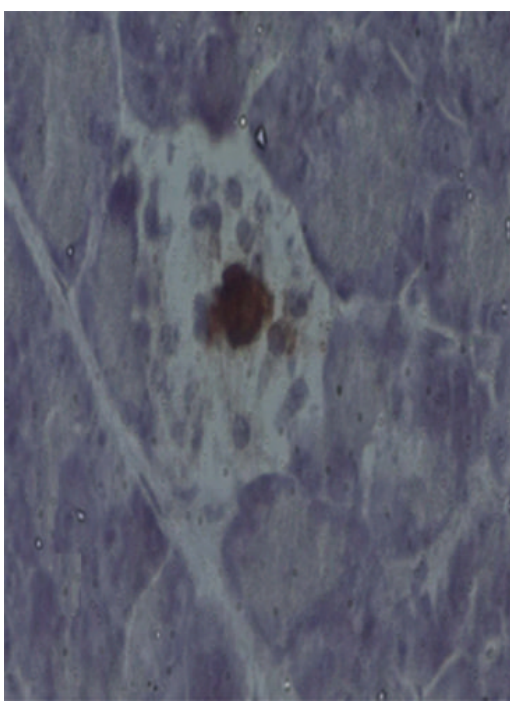

(a)

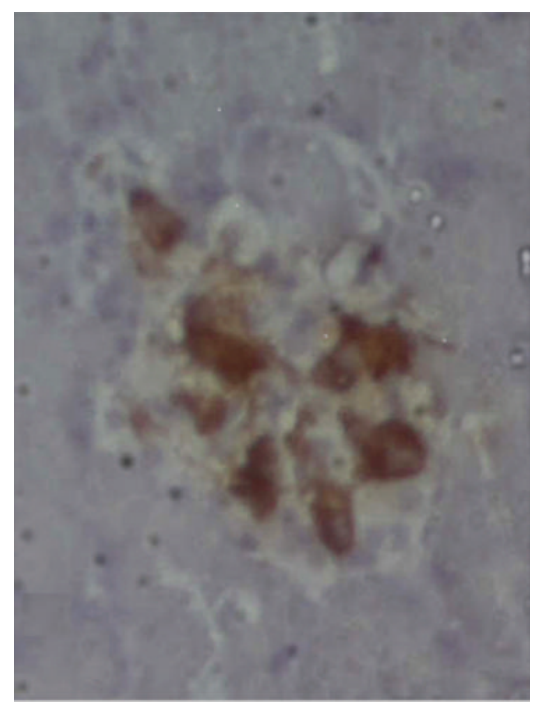

(b)

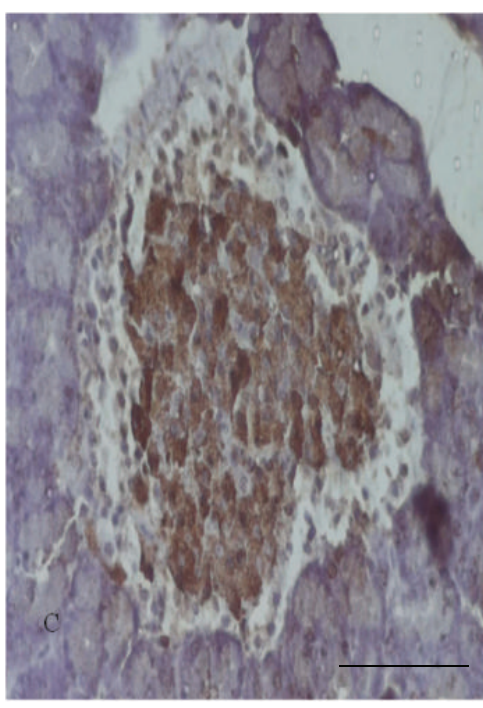

(c)

FIGURE 4: Immunohistochemical staining of insulin in pancreatic Langerhans islet beta cells from STZ-diabetic rats. Note that there are more insulin immunopositive cells in the treated STZ-diabetic rats than in nontreated STZ-diabetic rats. Control D (a), D treated with $5 \mathrm{mg} / \mathrm{Kg}$ of $\mathrm{VOSO}_{4}$ (b), and D treated with $10 \mathrm{mg} / \mathrm{Kg}$ of $\mathrm{VOSO}_{4}$ (c). Ten islets per rat were analyzed. Scale bar: $50 \mu \mathrm{m}$.

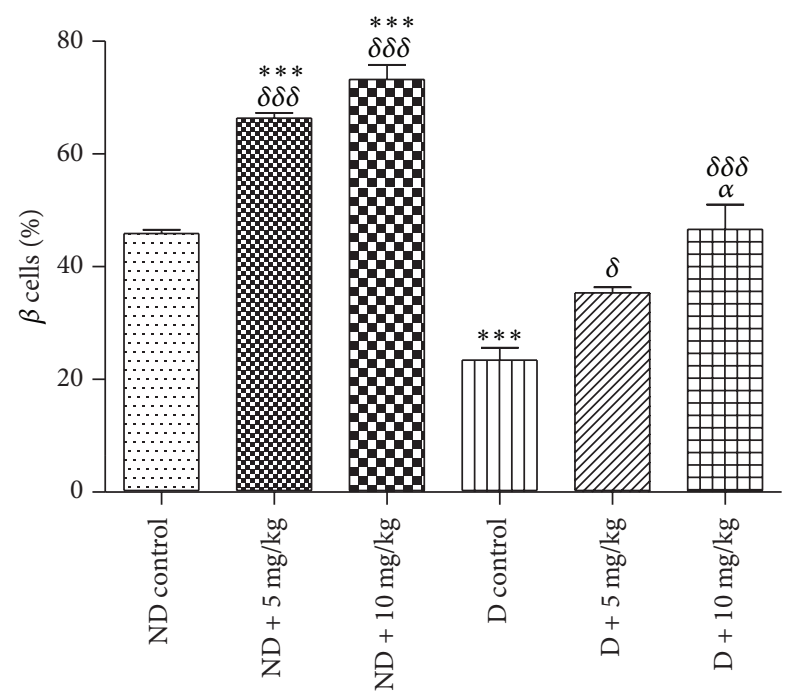

Figure 5: Effect of vanadyl sulfate on the number of beta cells in \%. Values represent mean $\pm \mathrm{SD} .{ }^{*} P<0.05 ;{ }^{* * *} P<0.001$ versus ND control. ${ }^{\delta} P<0.05 ;{ }^{\delta \delta \delta} P<0.001$ versus $\mathrm{D}$ control. ${ }^{\alpha} P<0.05$ versus $\mathrm{D}+5 \mathrm{mg} / \mathrm{Kg} .10$ islets per rat were analyzed.

mechanism of reduction of blood glucose levels by vanadium compounds is the activation of PKB/Akt kinase leading to the increase of glucose uptake by the GLUT4 transporter [34,38]. Activation of PKB/Akt stimulates also the phosphorylation of GSK3, resulting in the stimulation of glycogen synthesis $[34,39]$. On the other hand, it was found that inhibition of C-jun N-terminal kinase improves insulin sensitivity in experimental diabetes [40].
Vanadium increases glucose transport and oxidation and insulin-receptor tyrosine-kinase activity and exerts insulinlike effects on glucose and lipid metabolisms by insulindependent or insulin-independent biochemical pathways [9, $10,41]$.

It is well known that STZ treatment destroys beta cells of pancreatic islets inducing insulin-dependent diabetes mellitus $[19,22]$. Thus, in the present study, we showed a reduction in the area of pancreatic islets associated with a marked decrease in the number of immunoreactive beta cells for insulin in diabetic group in comparison with nondiabetic control animals. However, in both ND and D groups, $\mathrm{VOSO}_{4}$ treatment enlarged the size of pancreatic islets in comparison with respective control groups. Most importantly, $\mathrm{VOSO}_{4}$ treatment of diabetic rats increased in a dosedependent manner the number of insulin immunopositive beta cells as distinguished from diabetic untreated group, suggesting that $\mathrm{VOSO}_{4}$ can generate the beta cells in STZinduced diabetic rats. In fact, the number of beta cells in islets of diabetic $\mathrm{VOSO}_{4}$-treated rats with 5 and $10 \mathrm{mg}$ was not significantly different from that of ND group. This is in agreement with previous investigations concerning the pancreatic insulinotropic property of this compound $[18$, $24,42]$. Interestingly, vanadium treatment also increased significantly beta cells number in islets of nondiabetic rats.

In a mouse model of pancreas alloxan-perfused segment, Waguri et al. [43] reported processes of beta cells regeneration from extra-islet precursor cells. Indeed, in STZ-diabetic rats, $\mathrm{VOSO}_{4}$ treatment might stimulate beta cells proliferation from intraislet endocrine cells and differentiation from extraislet precursor cells.

In conclusion, the present study demonstrates that vanadyl sulfate could be useful as a potential antidiabetic agent. However, as the current evidences are still limited and 
based mostly on animal models and little is known about the therapeutic formulations and the side effects of vanadium compounds, further investigations on their long-term use as conventional therapy for diabetic patients are needed.

\section{Conflict of Interests}

The authors declare that there is no conflict of interests regarding the publication of this paper.

\section{Acknowledgment}

This work was supported by the Tunisian Ministry of Higher Education and Scientific Research.

\section{References}

[1] M. M. Shafer, B. M. Toner, J. T. Overdier et al., "Chemical speciation of vanadium in particulate matter emitted from diesel vehicles and urban atmospheric aerosols," Environmental Science and Technology, vol. 46, no. 1, pp. 189-195, 2012.

[2] T. Kiss, E. Kiss, E. Garribba, and H. Sakurai, "Speciation of insulin-mimetic $\mathrm{VO}(\mathrm{IV})$-containing drugs in blood serum," Journal of Inorganic Biochemistry, vol. 80, no. 1-2, pp. 65-73, 2000.

[3] R. Yanardag, S. Bolkent, Ö. Karabulut-Bulan, and S. Tunali, “ Effects of vanadyl sulfate on kidney in experimental diabetes," Biological Trace Element Research, vol. 95, no. 1, pp. 73-85, 2003.

[4] M. Koyuturk, S. Tunali, S. Bolkent, and R. Yanardag, "Effects of vanadyl sulfate on liver of streptozotocin-induced diabetic rats," Biological Trace Element Research, vol. 104, no. 3, pp. 233-247, 2005.

[5] Y. Niu, W. Liu, C. Tian et al., "Effects of bis( $\alpha$-furancarboxylato)oxovanadium(IV) on glucose metabolism in fat-fed/streptozotocin-diabetic rats," European Journal of Pharmacology, vol. 572, no. 2-3, pp. 213-219, 2007.

[6] D. Wei, M. Li, and W. Ding, "Effect of vanadate on gene expression of the insulin signaling pathway in skeletal muscle of streptozotocin-induced diabetic rats," Journal of Biological Inorganic Chemistry, vol. 12, no. 8, pp. 1265-1273, 2007.

[7] M. Li, J. J. Smee, W. Ding, and D. C. Crans, "Anti-diabetic effects of sodium 4-amino-2,6-dipicolinatodioxovanadium(V) dihydrate in streptozotocin-induced diabetic rats," Journal of Inorganic Biochemistry, vol. 103, no. 4, pp. 585-589, 2009.

[8] K. H. Thompson, J. Lichter, C. LeBel, M. C. Scaife, J. H. McNeill, and C. Orvig, "Vanadium treatment of type 2 diabetes: a view to the future," Journal of Inorganic Biochemistry, vol. 103, no. 4, pp. 554-558, 2009.

[9] V. Badmaev, S. Prakash, and M. Majeed, "Vanadium: a review of its potential role in the fight against diabetes," Journal of Alternative and Complementary Medicine, vol. 5, no. 3, pp. 273291, 1999.

[10] M. C. Cam, R. W. Brownsey, and J. H. McNeill, "Mechanisms of vanadium action: insulin-mimetic or insulin-enhancing agent?" Canadian Journal of Physiology and Pharmacology, vol. 78, no. 10, pp. 829-847, 2000.

[11] H. A. Sakurai, K. Tsuchiya, M. Nukatsuka, M. Sofue, and J. Kawada, "Insulin-like effect of vanadyl ion on streptozotocininduced diabetic rats," Journal of Endocrinology, vol. 126, no. 3, pp. 451-459, 1990.
[12] M. T. Conconi, E. Decarlo, S. Vigolo et al., "Effects of some vanadyl coordination compounds on the in vitro insulin release from rat pancreatic islets," Hormone and Metabolic Research, vol. 35, no. 7, pp. 402-406, 2003.

[13] Y. Shechter, I. Goldwaser, M. Mironchik, M. Fridkin, and D. Gefel, "Historic perspective and recent developments on the insulin-like actions of vanadium; toward developing vanadiumbased drugs for diabetes," Coordination Chemistry Reviews, vol. 237, no. 1-2, pp. 3-11, 2003.

[14] N. Venkatesan, A. Avidan, and M. B. Davidson, "Antidiabetic action of vanadyl in rats independent of in vivo insulin-receptor kinase activity," Diabetes, vol. 40, no. 4, pp. 492-498, 1991.

[15] E. Tsiani and I. G. Fantus, "Vanadium compounds: biological actions and potential as pharmacological agents," Trends in Endocrinology and Metabolism, vol. 8, no. 2, pp. 51-58, 1997.

[16] S. Verma, M. C. Cam, and J. H. McNeill, "Nutritional factors that can favorably influence the glucose/insulin system: vanadium," Journal of the American College of Nutrition, vol. 17, no. 1, pp. $11-18,1998$.

[17] D. Rehder, "Biological and medicinal aspects of vanadium," Inorganic Chemistry Communications, vol. 6, no. 5, pp. 604-617, 2003.

[18] M. Bendayan and D. Gingras, "Effect of vanadate administration on blood glucose and insulin levels as well as on the exocrine pancreatic function in streptozotocin-diabetic rats," Diabetologia, vol. 32, no. 8, pp. 561-567, 1989.

[19] G. A. Dehghani, M. Sotoodeh, and G. R. Omrani, "Trophic effects of vanadium on beta-cells of STZ-induced insulindependent diabetic rats and evidence for long term relief of diabetes mellitus," Indian Journal of Medical Research, vol. 110, pp. 70-75, 1999.

[20] A. K. Srivastava, "Anti-diabetic and toxic effects of vanadium compounds," Molecular and Cellular Biochemistry, vol. 206, no. 1-2, pp. 177-182, 2000.

[21] J. J. Mongold, G. H. Cros, L. Vian et al., “Toxicological aspects of vanadyl sulphate on diabetic rats: effects on vanadium levels and pancreatic B-cell morphology," Pharmacology and Toxicology, vol. 67, no. 3, pp. 192-198, 1990.

[22] J. Yao, M. L. Battell, and J. H. McNeill, "Acute and chronic response to vanadium following two methods of streptozotocin-diabetes induction," Canadian Journal of Physiology and Pharmacology, vol. 75, no. 2, pp. 83-90, 1997.

[23] K. Akgün-Dar, S. Bolkent, R. Yanardag, and S. Tunali, "Vanadyl sulfate protects against streptozotocin-induced morphological and biochemical changes in rat aorta," Cell Biochemistry and Function, vol. 25, no. 6, pp. 603-609, 2007.

[24] S. Bolkent, S. Bolkent, R. Yanardag, and S. Tunali, "Protective effect of vanadyl sulfate on the pancreas of streptozotocininduced diabetic rats," Diabetes Research and Clinical Practice, vol. 70, no. 2, pp. 103-109, 2005.

[25] C. E. Heyliger, A. G. Tahiliani, and J. H. McNeill, "Effect of Vanadate on elevated blood glucose and depressed cardiac performance of diabetic rats," Science, vol. 227, no. 4693, pp. 1474-1477, 1985.

[26] G. A. Dehghani, S. Ahmadi, and G. R. Omrani, "Effects of vanadyl sulphate on glucose homeostasis in severe diabetes induced by streptozotocin in rats," Indian Journal of Medical Research, vol. 106, pp. 481-485, 1997.

[27] E. Shafrir, S. Spielman, I. Nachliel, M. Khamaisi, H. Bar-On, and E. Ziv, "Treatment of diabetes with vanadium salts: general overview and amelioration of nutritionally induced diabetes in 
the Psammomys obesus gerbil," Diabetes/Metabolism Research and Reviews, vol. 17, no. 1, pp. 55-66, 2001.

[28] M. Huang, Y. Wu, N. Wang, Z. Wang, Yang X., and P. Zhao, "Is the hypoglycemic action of vanadium compounds related to the suppression of feeding?" Biological Trace Element Research, vol. 157, no. 3, pp. 242-248, 2014.

[29] M. Xie, D. Chen, F. Zhang, G. R. Willsky, D. C. Crans, and W. Ding, "Effects of vanadium (III, IV, V)-chlorodipicolinate on glycolysis and antioxidant status in the liver of STZ-induced diabetic rats," Journal of Inorganic Biochemistry, vol. 136, pp. 4756, 2014.

[30] M. Soveid, G. A. Dehghani, and G. R. Omrani, "Long- term efficacy and safety of vanadium in the treatment of type 1 diabetes," Archives of Iranian Medicine, vol. 16, no. 7, pp. 408411, 2013.

[31] J. Meyerovitch, Z. Farfel, J. Sack, and Y. Shechter, "Oral administration of vanadate normalizes blood glucose levels in streptozotocin-treated rats. Characterization and mode of action," Journal of Biological Chemistry, vol. 262, no. 14, pp. 6658-6662, 1987.

[32] A. B. Goldfine, D. C. Simonson, F. Folli, M. E. Patti, and C. R. Kahn, "In vivo and in vitro studies of vanadate in human and rodent diabetes mellitus," Molecular and Cellular Biochemistry, vol. 153, pp. 217-231, 1995.

[33] M. C. Cam, B. Rodrigues, and J. H. McNeill, "Distinct glucose lowering and beta cell protective effects of vanadium and food restriction in streptozotocin-diabetes," European Journal of Endocrinology, vol. 141, no. 5, pp. 546-554, 1999.

[34] G. Vardatsikos, M. Z. Mehdi, and A. K. Srivastava, "Bis(maltolato)-oxovanadium (IV)-induced phosphorylation of PKB, GSK-3 and FOXO1 contributes toits glucoregulatory responses," International Journal of Molecular Medicine, vol. 24, no. 3, pp. 303-309, 2009.

[35] D. C. Crans, J. J. Smee, E. Gaidamauskas, and L. Yang, "The chemistry and biochemistry of vanadium and the biological activities exerted by vanadium compounds," Chemical Reviews, vol. 104, no. 2, pp. 849-902, 2004.

[36] T. Scior, J. A. Guevara-García, F. J. Melendez, H. H. Abdallah, Q. T. Do, and P. Bernard, "Chimeric design, synthesis, and biological assays of a new nonpeptide insulin-mimetic vanadium compound to inhibit protein tyrosine phosphatase 1B," Drug Design, Development and Therapy, vol. 4, pp. 231-242, 2010.

[37] T. Scior, H. Mack, J. A. G. García, and W. Koch, "Antidiabetic bis-maltolato-oxovanadium(IV): conversion of inactive transto bioactive cis-BMOV for possible binding to target PTP-1B," Drug Design, Development and Therapy, vol. 2, pp. 221-231, 2008.

[38] A. Mohammad, V. Sharma, and J. H. McNeill, "Vanadium increases GLUT4 in diabetic rat skeletal muscle," Molecular and Cellular Biochemistry, vol. 233, no. 1-2, pp. 139-143, 2002.

[39] S. Semiz and J. H. McNeill, "Oral treatment with vanadium of Zucker fatty rats activates muscle glycogen synthesis and insulin-stimulated protein phosphatase-1 activity," Molecular and Cellular Biochemistry, vol. 236, no. 1-2, pp. 123-131, 2002.

[40] A. Ijaz, T. Tejada, P. Catanuto et al., "Inhibition of C-jun N-terminal kinase improves insulin sensitivity but worsens albuminuria in experimental diabetes," Kidney International, vol. 75, no. 4, pp. 381-388, 2009.

[41] A. B. Goldfine, M. E. Patti, L. Zuberi et al., "Metabolic effects of vanadyl sulfate in humans with non-insulin-dependent diabetes mellitus: in vivo and in vitro studies," Metabolism, vol. 49, no. 3 , pp. $400-410,2000$.
[42] S. Ahmadi, S. M. Karimian, M. Sotoudeh, M. Bahadori, and G. A. Dehghani, "Pancreatic islet beta cell protective effect of oral vanadyl sulphate in streptozotocin -induced diabetic rats, an ultrastructure study," Pakistan Journal of Biological Sciences, vol. 13, no. 23, pp. 1135-1140, 2010.

[43] M. Waguri, K. Yamamoto, J. Miyagawa et al., "Demonstration of two different processes of $\beta$-cell regeneration in a new diabetic mouse model induced by selective perfusion of alloxan," Diabetes, vol. 46, no. 8, pp. 1281-1290, 1997. 


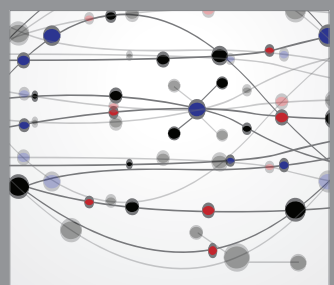

The Scientific World Journal
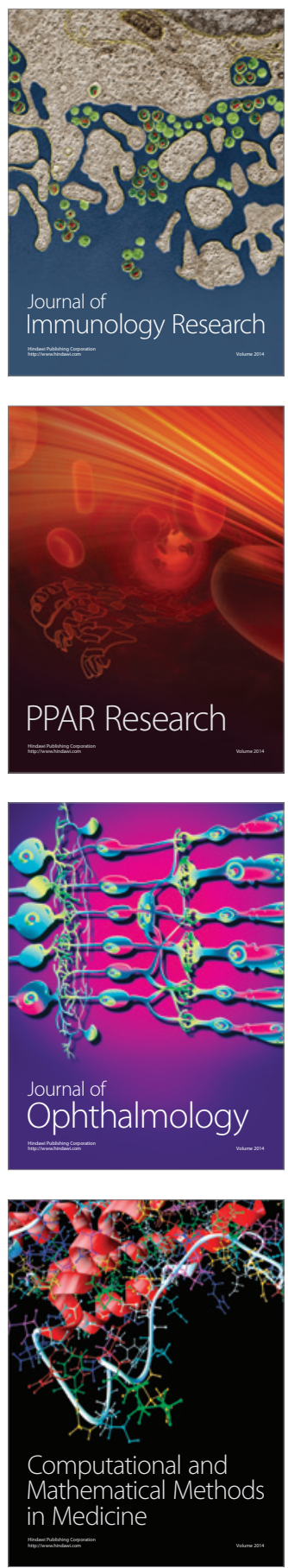

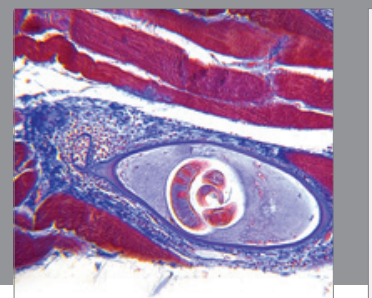

Gastroenterology

Research and Practice
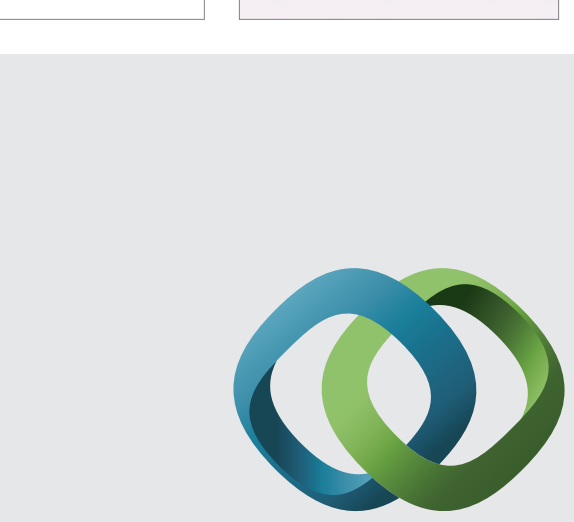

\section{Hindawi}

Submit your manuscripts at

http://www.hindawi.com
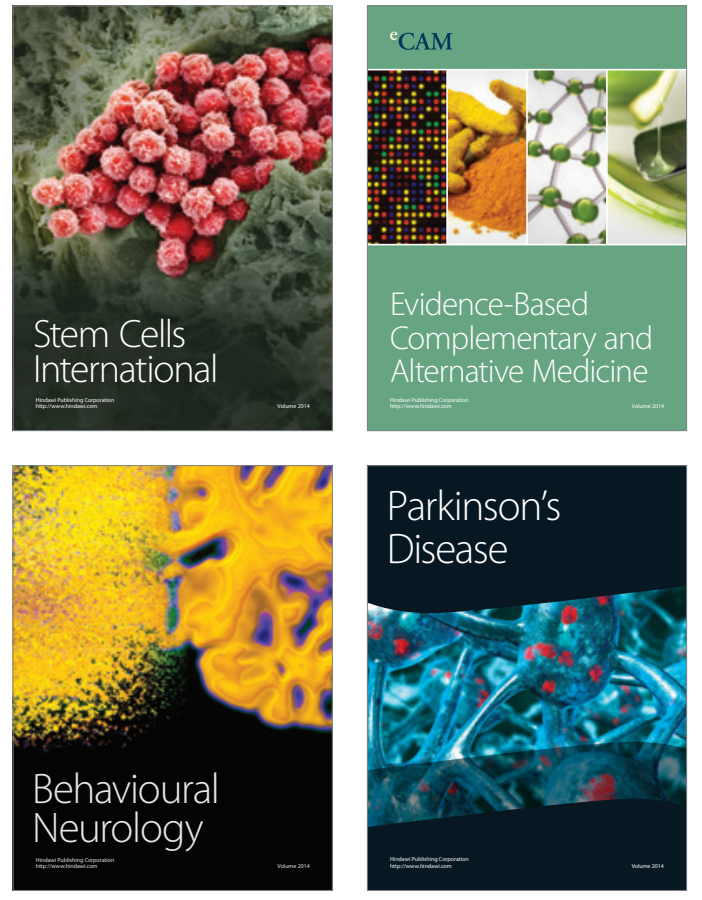
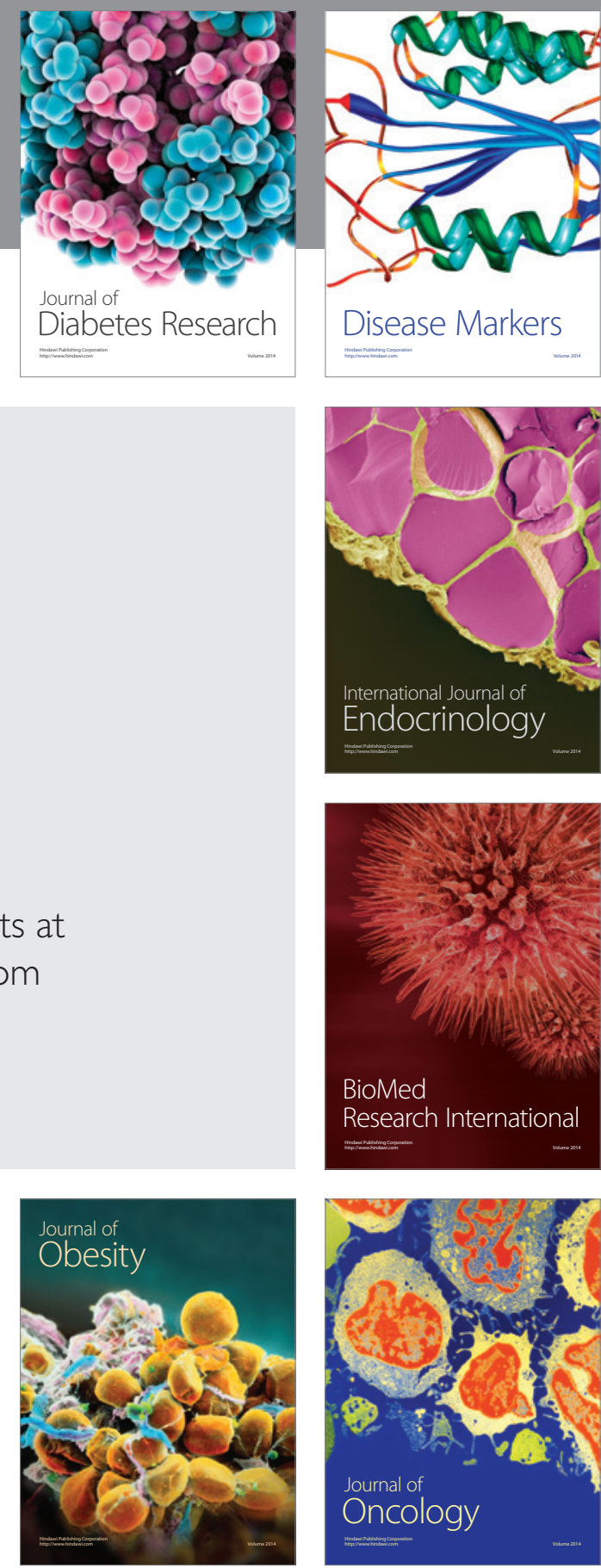

Disease Markers
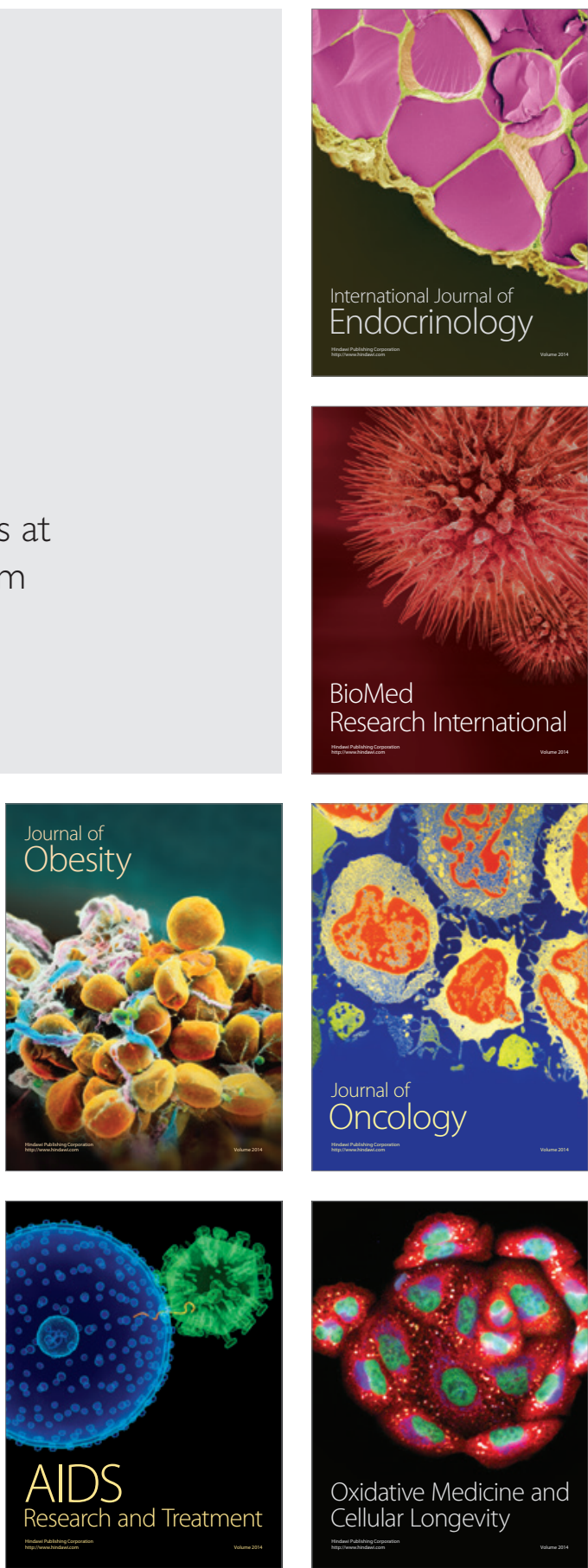